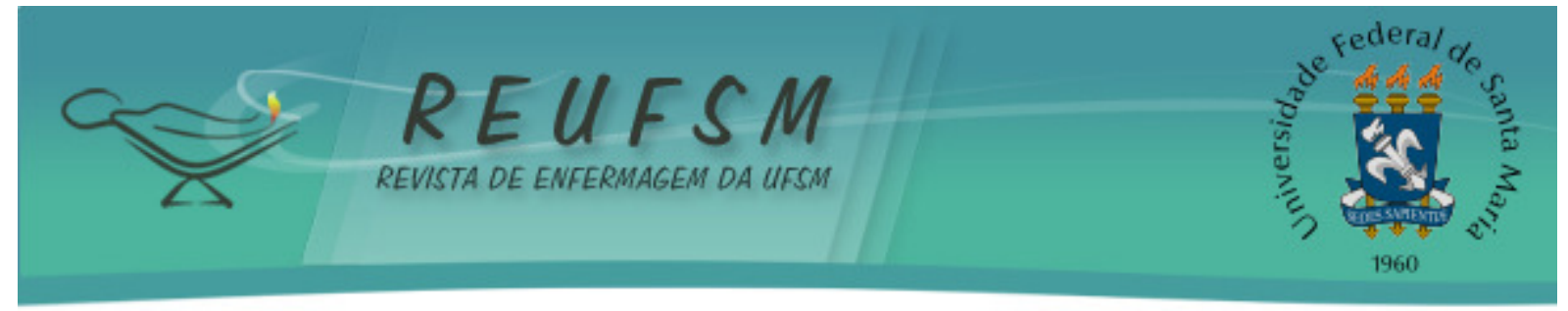

ARTIGO ORIGINAL

\title{
EDUCAÇÃO PERMANENTE EM SAÚDE: PERCEPÇÃO DE PROFISSIONAIS DE UMA RESIDÊNCIA MULTIDISCIPLINAR
}

\author{
PERMANENT EDUCATION IN HEALTH: PERCEPTION OF PROFESSIONALS IN THE \\ MULTIDISCIPLINAR RESIDENCE
}

\section{EDUCACIÓN PERMANENTE EN SALUD: PERCEPCIÓN DE LOS PROFESIONALES DE UNA RESIDENCIA MULTIDISCIPLINAR}

\author{
Cristiane Trivisiol da Silva ${ }^{1}$ \\ Marlene Gomes Terra ${ }^{2}$ \\ Camila Castro Roso ${ }^{3}$ \\ Valquiria Toledo Souto ${ }^{4}$
}

Doi: $10.5902 / 2179769211067$

RESUMO: Objetivo: conhecer a percepção dos profissionais integrantes de uma residência multiprofissional sobre a Educação Permanente em Saúde. Método: pesquisa qualitativa, descritiva e exploratória, do tipo Estudo de Caso, realizado por meio de observação de campo, pesquisa documental e entrevista semiestruturada, com 17 profissionais integrantes de uma residência multiprofissional. Resultados: os depoimentos indicam que a residência multiprofissional em saúde é um espaço que possibilita a integração teoria e prática como desencadeadora da Educação Permanente em Saúde que, por sua vez, é articulada pelos segmentos da atenção e gestão para a produção de saúde. Considerações finais: destaca-se a percepção da educação permanente além de uma perspectiva pontual, sendo desencadeada por espaços nos quais atores dialogam acerca da educação permanente, a fim de que esta possa contribuir para o desenvolvimento de competências para atuação no Sistema Único de Saúde.

Descritores: Enfermagem; Educação continuada; Estudos de casos; Internato e residência; Políticas públicas de saúde.

ABSTRACT: Aim: to know the perception of professional members of a multiprofessional residence about permanent education in health. Method: the study is characterized as a qualitative, descriptive and exploratory research, type case study, conducted through field observation, documentary research and semi-structured interview, with 17 professionals members of a multiprofessional residence. Results: the evidence shows that the multiprofessional residence in health it's a space that enables integration theory and practice as a trigger of Continuing Education in Health, which, in turn, is articulated by segments of attention for the production and management of health. Conclusion: it's highlightened the perception of permant education beyond a punctual perspective, being trigged by spaces in which the actors discuss about permanent education, so that it can contribute to the development of competencies to act on the Public Health System.

Descriptors: Nursing; Continuing, education; Case studies; Internship and residency; Health public policy.

\footnotetext{
${ }^{1}$ Enfermeira. Mestre em Enfermagem. Doutoranda do Programa de Pós-graduação em Enfermagem da Universidade Federal do Rio Grande do Sul (PPGEnf/UFRGS). Bolsista Capes. E-mail: cris.trivisiol@gmail.com

${ }^{2}$ Enfermeira. Doutora em Enfermagem. Professora adjunta do Curso de Graduação e do Programa de PósGraduação em Enfermagem (PPGEnf) da Universidade Federal de Santa Maria (UFSM,RS,Brasil).E-mail: martesm@hotmail.com.br

${ }^{3}$ Enfermeira. Mestre em Enfermagem. Doutoranda do Programa de Pós-graduação em Enfermagem da Universidade Federal do Rio Grande do Sul (PPGEnf/UFRGS). E-mail: camilaroso@yahoo.com.br

${ }^{4}$ Enfermeira. Mestranda do Programa de Pós-graduação de Enfermagem (PPGEnf) da Universidade Federal de Santa Maria (UFSM,RS,Brasil). E-mail: valquiriatoledo@hotmail.com
} 


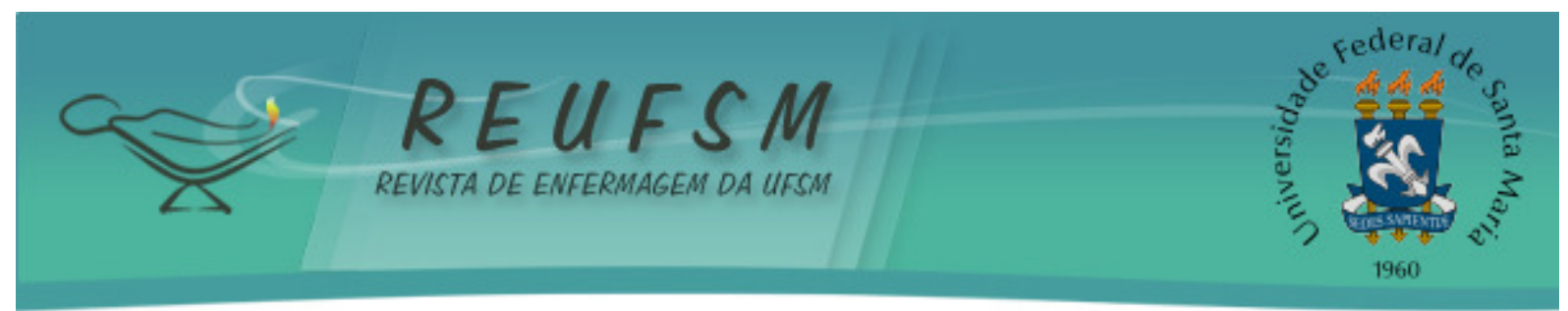

RESUMEN: Objetivo: conocer la percepción de los profesionales de una residencia multiprofesional acerca de la Educación Permanente en Salud. Método: investigación cualitativa, descriptiva y exploratoria, del tipo estudio de caso, realizado por medio de la observación de campo, pesquisa documental y entrevista semiestructurada, con 17 profesionales de una residencia multiprofesional. Resultados: los testimonios indican que la residencia multiprofesional en salud es un espacio que posibilita la integración teoría y práctica, como un disparador de la Educación Permanente en Salud, que a su vez es constituido por segmentos articulados de la atención y el manejo de la producción de la salud. Consideraciones finales: destaca la percepción de la educación permanente, más allá de una perspectiva de punto, que se desencadena por espacios en los cuales los actores hablan sobre la formación permanente para que puedan contribuir al desarrollo de las habilidades para operar en el Sistema Único de Salud.

Descriptores: Enfermería; Educación continua; Estudios de casos; Internado y residencia; Políticas públicas de salud.

\section{INTRODUÇÃO}

O Sistema Único de Saúde (SUS), atual protagonista na construção das políticas orientadoras da formação, desenvolvimento, distribuição, regulação e gestão dos profissionais de saúde, tem fortificado sua preocupação com a lógica da saúde individual e coletiva prestada aos usuários. A fim de alcançar a consolidação de seus princípios, uma das estratégias difundidas pelo SUS foi a criação da Política Nacional de Educação Permanente em Saúde (PNEPS). ${ }^{1-2}$

A PNEPS, desenvolvida a partir do ano de 2004 e reformulada em 2007, se insere no SUS com o objetivo de aproximar suas ações e serviços com as instituições formadoras, no sentido de promover mudanças na formação em saúde e provocar alterações nas práticas dominantes dos sistemas de saúde, através da problematização de suas próprias práticas e do trabalho em equipe. ${ }^{1}$ Ainda que tenha sofrido alterações na sua constituição desde sua emergência, seu principal foco continua sendo a transformação de práticas reais pautado nas necessidades da população. ${ }^{2}$ Assim, busca possibilitar reflexões e transformações, a partir da educação no trabalho, convidando a todos (cidadãos, usuários e profissionais de saúde) a participarem das mudanças na gestão, na sociedade e no controle social.

Além disso, a PNEPS possibilita que a formação e o desenvolvimento de profissionais de saúde ocorram de modo descentralizado, ascendente e transdisciplinar, englobando todos os locais e saberes, a fim de proporcionar a democratização dos espaços de trabalho. ${ }^{2}$ Nesse sentido, a PNEPS pode ser compreendida como um dispositivo para transformação da área da saúde, em que as ações são em busca de uma melhoria do padrão de assistência à saúde. ${ }^{3}$

A criação da PNEPS ainda suscita discussões sobre a temática da formação e desenvolvimento dos profissionais de saúde no Brasil, que se encontra em vários movimentos em direção a mudanças. ${ }^{4-6}$ Entre as mudanças almejadas busca-se promover a formação de profissionais de saúde que atendam as demandas do SUS. Para isso, uma alternativa foi a criação da Residência Multiprofissional em Saúde (RMS), dispositivo de transformação das práticas da área da saúde, que busca proporcionar, na continuidade da formação dos profissionais, a qualificação para o trabalho voltado para o SUS.

A RMS tem como objetivo a formação de profissionais para uma atuação diferenciada no SUS, com construção interdisciplinar, trabalho em equipe, educação permanente e consequente reorientação das lógicas tecnoassistenciais. ${ }^{6}$ Desta forma, o SUS torna-se interlocutor na formulação dos projetos político-pedagógicos de formação dos trabalhadores, proporcionando práticas condizentes com seus princípios, e deixando de ser considerado apenas como um campo de práticas. ${ }^{1}$ Acredita-se que a Educação Permanente 


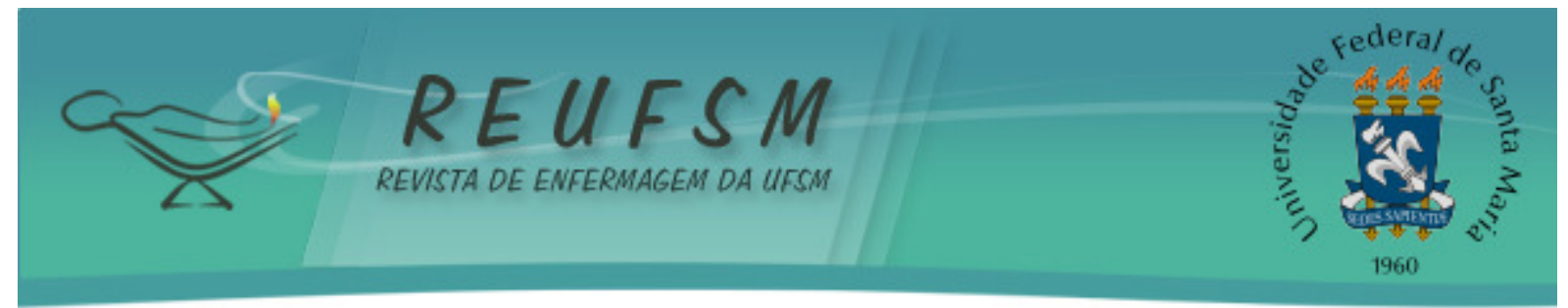

em Saúde (EPS) venha a qualificar a formação profissional e fortalecer o SUS, ao passo que assegura o desenvolvimento dos trabalhadores e instituições de saúde.

Este estudo se justifica na possibilidade de explorar o espaço de formação que a residência propõe para a qualificação de profissionais para o SUS. Ainda, entender como estes profissionais percebem a PNEPS, em um cenário no qual ainda há entraves que dificultam a consolidação de suas ações pautadas nos princípios do SUS.

Nesse sentido, elege-se como questão de pesquisa: como os profissionais integrantes de uma residência multiprofissional percebem a Educação Permanente em Saúde em seu cotidiano de atuação? E como objetivo: conhecer a percepção dos profissionais integrantes de uma residência multiprofissional sobre a Educação Permanente em Saúde.

\section{MÉTODO}

Estudo descritivo, exploratório, de abordagem qualitativa. Utilizou-se o método de Estudo de Caso, o qual permite a realização da pesquisa de fenômenos dentro do seu contexto real, analisando intensamente uma unidade social. ${ }^{7}$

Os sujeitos foram 17 profissionais de saúde, integrantes do Programa da Residência Multiprofissional Integrada em Sistema Público de Saúde (RMISPS) de concentração na área hospitalar, contemplando residentes e preceptores de núcleo e campo das seguintes categorias profissionais: Enfermagem, Psicologia, Nutrição, Serviço Social, Fonoaudiologia, Farmácia, Terapia Ocupacional, Odontologia e Educação Física. A RMISPS é desenvolvida em um hospital de ensino localizado num município no interior do Estado do Rio Grande do Sul, no Brasil.

A coleta de dados foi realizada no período de janeiro a maio do ano de 2012. Inicialmente, foi realizada pesquisa documental, procurando registros que revelassem evidências acerca dos princípios de EPS no Projeto Pedagógico do programa da RMISPS. Concomitantemente à pesquisa documental, foi realizada a observação do campo, que se deu nos seminários de campo e núcleo, nos quais as atividades dos residentes eram planejadas e discutidas. Na sequência, foram realizadas entrevistas individuais, com a intenção de aprofundar a busca de dados sobre o objeto de estudo, com a seguinte questão norteadora: como você percebe a Educação Permanente em Saúde no seu cotidiano de atuação?

Como critérios de inclusão para a entrevista estabeleceu-se: ser profissional vinculado a RMISPS, atuante na atenção hospitalar no período de coleta de dados. E, como critérios de exclusão: sujeitos que estivessem em período de férias ou em atestado médico no período da coleta de dados.

Para análise dos dados foi utilizado o programa de análise de dados qualitativos Software Atlas Ti 6.2 (Qualitative Research and Solutions) uma ferramenta de pesquisa que permite identificar os indicadores de sentido, o qual auxilia no processo de codificação e recodificação dos temas. A partir disso, os dados foram reunidos para análise, constando de uma cópia dos documentos oriundos da análise documental, diário de campo da pesquisadora, utilizado no processo de observação e transcrição das entrevistas (gravadas e transcritas pela própria pesquisadora). Após, este material foi analisado por meio da Análise Temática, passando pelas seguintes fases: pré-análise, exploração do material e tratamento dos resultados obtidos. ${ }^{8}$

0 protocolo do projeto de pesquisa atendeu os preceitos éticos da Resolução Conselho Nacional de Saúde $N^{\circ} 196 / 96$ e foi aprovado pelo Comitê de Ética em Pesquisa, no dia 13 de março de 2012 sob Certificado Apresentação para Apreciação Ética $\mathrm{n}^{\circ}$ 0147012.4.0000.5346. ${ }^{9}$ Ressalta-se que todos os participantes assinaram o Termo de Consentimento Livre e Esclarecido. A fim de preservar o anonimato dos participantes, as falas foram identificadas com a letra "E" de entrevista, acompanhada de um número ordinal de acordo com a sequência das entrevistas. 


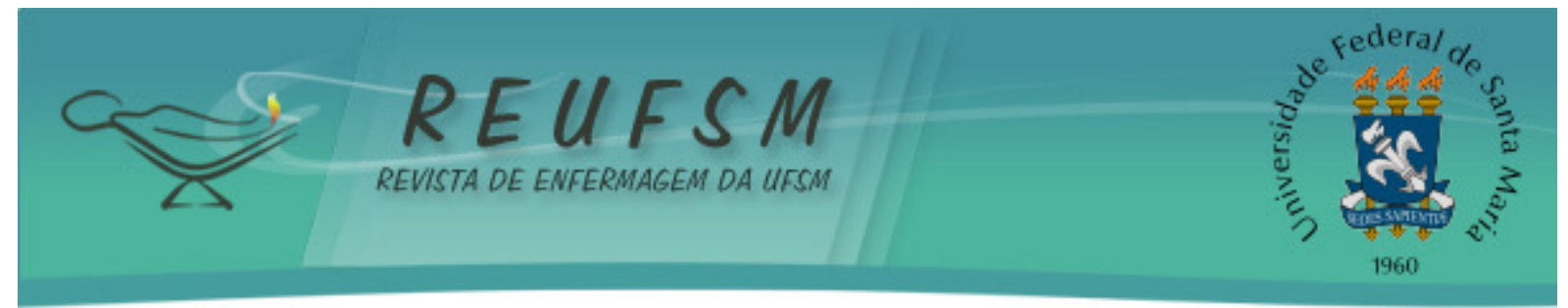

\section{RESULTADOS E DISCUSSÃO}

Os depoimentos dos profissionais integrantes da residência multiprofissional possibilitaram construir dois núcleos temáticos: Educação Permanente em Saúde como dispositivo de integração teoria e prática e Educação Permanente em Saúde como articulação entre as esferas de gestão e atenção.

\section{Educação Permanente em Saúde como dispositivo de integração teoria e prática}

A formação em saúde ainda é "um dos grandes nós críticos" das propostas que apostam na mudança do modelo tecnoassistencial em saúde no Brasil, "que tem se mostrado comprometido com muitos tipos de interesse, exceto com a saúde dos cidadãos". ${ }^{10: 71}$ A EPS aposta na formação dos profissionais como parte de um projeto de transformação, com mudanças na forma de compreender a educação e a construção de saberes. ${ }^{11}$

A mudança da lógica ainda presente nas instituições formadoras, da dicotomia entre teoria e prática, é defendida pela EPS com intuito de promover uma rede de saberes entre os vários campos de conhecimento. Em consonância com essa proposta, o entendimento dos profissionais da RMISPS salientam a integração teoria e prática como desencadeadora da EPS, sendo uma evidência positiva na formação que estes recebem:

Acho que a educação permanente ela vai muito voltada para a educação no serviço [...] e acho que a residência ela permite de tu além de ter uma teoria, tu ter a prática. (E9)

Ao entender-se a EPS como uma estratégia para a transformação profissional, pode-se dizer que esta ocorre pela articulação entre a teoria e a prática, agregada a política institucional a que os trabalhadores fazem parte. ${ }^{12} \mathrm{~A}$ EPS, como percebida pelos profissionais da RMISPS, permite que estes reflitam acerca de suas experiências vividas nos serviços de saúde, estabelecendo relações da teoria com a realidade vivenciada, possibilitando que suas ações possam ser transformadas e realizadas a partir do processo prática-reflexão-práxis. ${ }^{11}$

Com relação à importância da integração teoria e prática, também se pode observar que os seminários de núcleo e campo constituíram-se em espaços fundamentais para a discussão das práticas vivenciadas na realidade dos serviços de saúde e a realização das associações teóricas. Neste sentido, os preceptores tornam-se importantes disparadores da relação teoria e prática nos seminários e nos serviços de saúde. Conforme salientado no Projeto Político Pedagógico (PPPC) do referido programa, os preceptores e residentes precisam discutir a realidade, buscando uma consciência crítica, individual e coletiva. 0 depoimento corrobora com a evidência observada:

Acredito que o maior espaço de formação, tanto teórica quanto prática, seja num campo prático, que essa aproximação com a teoria que a gente vive na prática acontece nos seminários de núcleo, principalmente, $e$ em discussões de caso que são promovidas pelos próprios residentes e pelos preceptores. (E10)

É possível observar que os princípios da EPS estão presentes em todo processo formativo dos residentes, tanto no PPPC quanto nos depoimentos dos profissionais da RMISPS e nas observações realizadas. Porém, poucos residentes sinalizaram a discussão da PNEPS no espaço da sala de aula ou de disciplinas que abordavam de forma indireta a educação permanente em saúde: 


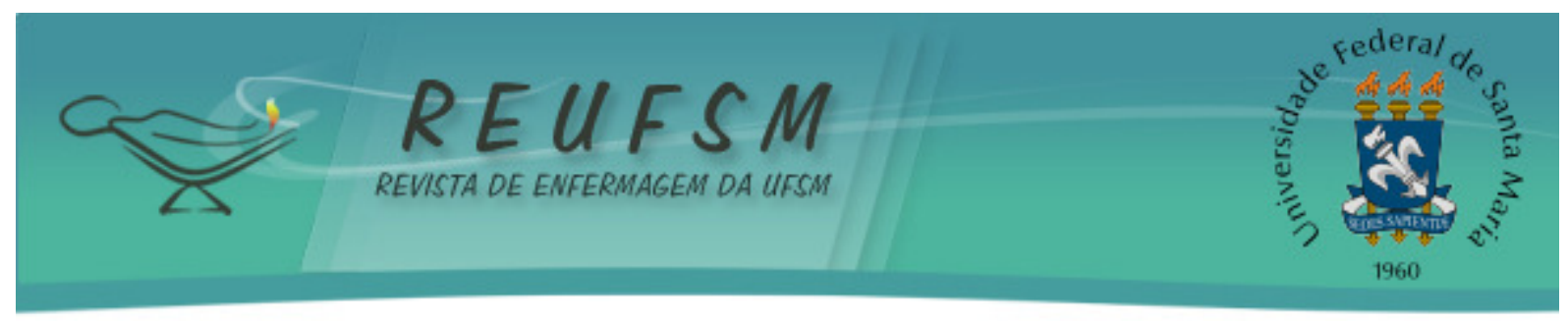

Algumas disciplinas também promoviam essa reflexão, esse aprendizado da prática com a teoria. (E1)

Sim, em algumas aulas a gente já discutiu sobre a EPS. Até na aula da Professora $X$ também a gente discutiu, e fez alguns debates trazendo a prática para dentro da teoria enfim. Tentando articular as duas, em algumas aulas sim. (E12)

A busca de articulação entre teoria e prática na formação em saúde esbarra em um descompasso entre a formação acadêmica e a prática real do cotidiano nas redes dos serviços de saúde. Isto é apontado como um dos responsáveis pela crise no setor saúde, e constitui-se em problema grave para a efetivação do SUS. ${ }^{2}$ Nesse sentido, mais uma vez atenta-se para a formação de profissionais em saúde para o SUS como um dos eixos estratégicos para a construção do sistema. ${ }^{13}$

Uma das questões formalizadas em relação à necessidade da inclusão de outras dimensões de aprendizagem na formação dos trabalhadores foi a publicação das Diretrizes Curriculares Nacionais (DCN) para os cursos de graduação da área da saúde instituída pelo Ministério da Educação, em 2001. ${ }^{14}$ Os projetos pedagógicos dos cursos devem incluir ao perfil dos profissionais da saúde, além da competência técnica condizente a cada núcleo profissional, a criticidade e a reflexividade frente às práticas cuidadoras. Mas, como as instituições de ensino buscam contemplar estas características na formação destes profissionais?

Sabe-se que, além dos referenciais dos processos educativos, os profissionais de saúde são potências de autopoder, de autogestão na micropolítica do trabalho vivo em ato e podem (ou não) intervir na construção e efetivação do sistema. ${ }^{15} \mathrm{~A}$ micropolítica é entendida como o agir cotidiano dos sujeitos na relação entre si e no cenário em que ele se encontra ${ }^{15}$ e como potência instituinte das ações em saúde que revela um mundo não estruturado e de alta capacidade inventiva. ${ }^{16}$

Assim, tendo em vista os graus significativos de liberdade no agir cotidiano, os profissionais fazem opções ético-tecnológicas e políticas incessantemente. Estas podem ser tanto conservadoras, numa militância de negação do SUS, como em prol de um projeto diferenciado de saúde e em defesa da vida. ${ }^{14}$ Além disso, a formação e o desenvolvimento dos profissionais de saúde também necessita envolver aspectos pessoais, valores, ideias que cada um tem acerca do SUS. ${ }^{2}$ Nesse sentido, destaca-se a Educação Permanente como um processo político que coloca em ato uma prática de encontro entre profissionais, por meio da produção de conhecimentos em saúde, das suas ações, pensamentos e desejos de protagonismo pelo SUS. ${ }^{17}$

\section{Educação Permanente em Saúde como articulação entre as esferas de gestão e atenção}

Tradicionalmente, o setor da saúde trabalha com a política de modo fragmentado: saúde coletiva separada da clínica, gestão separada da atenção, atenção separada da vigilância e, assim por diante, em que cada um destes fragmentos é dividido em tantas áreas técnicas quanto sejam os campos de saber especializado. ${ }^{18} \mathrm{~A}$ EPS integra todos os segmentos de formação, atenção, gestão e do controle social de forma que, a partir desta integração, se possa pensar na produção de saúde.

Assim, os depoimentos dos profissionais da RMISPS sinalizam a percepção da EPS como uma forma de articulação entre as esferas de gestão e atenção:

A residência está unindo bastante a atenção básica com o hospital, e a gente está tentando criar este vínculo. Tudo isso através de 


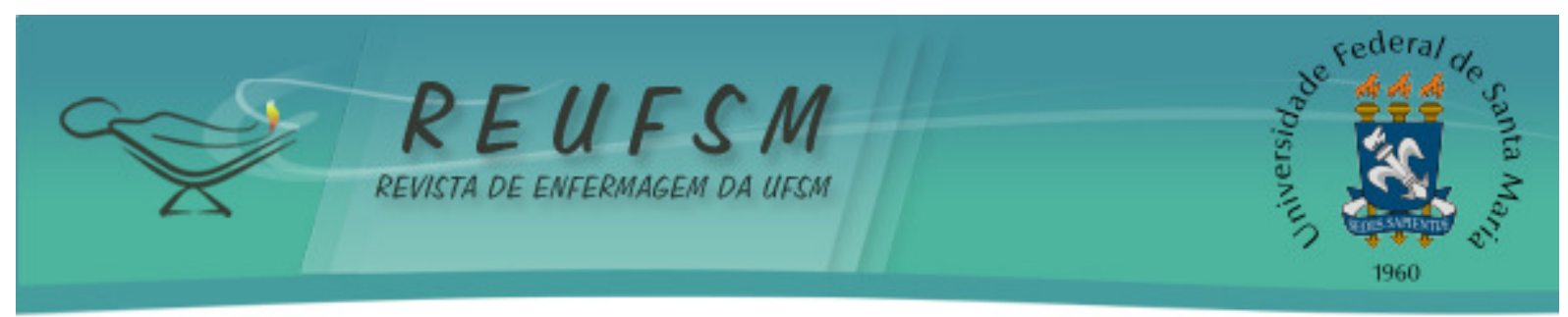

grupos de estudo de educação, de cursos. Então tudo isso é a educação permanente. (E4)

A questão que eu vejo, ainda mais demorada e um pouco difícil, é de a gente conseguir concretizar a ponte, porque nosso objetivo não é dar alta para paciente, é transferir ele para a unidade, e isso a gente está tentando colocar como objetivo mais forte! Essa é uma forma de a gente poder melhorar isso, e vem agora, com a residência que tem a rede com as práticas lá, e que a gente tinha que sentar mais junto. (E8)

A implementação de políticas efetivas de EPS é importante para serem revistas as formas de gestão e de atenção, dos serviços e processos formativos, das práticas de saúde e pedagógicas e, especificamente, o processo de trabalho. ${ }^{19}$ Nos seminários com os residentes, percebeu-se a preocupação destes profissionais para que suas ações fossem pautadas na articulação da esfera da atenção com a gestão, pois se espera do residente a competência de agir como articulador participativo dos processos de mudanças de saúde.

É importante salientar a ideia de autogestão incorporada a política de EPS, uma vez que há o reconhecimento de que os lugares de produção de saúde são também lugares em autogestão, onde é possível ser ator no cotidiano do serviço em que se está inserido, e não apenas assistir como expectador da cogestão. Se pensados desta forma, os profissionais integrantes da RMISPS seriam disparadores de ações de EPS em toda a rede de ensino e serviço incorporada ao SUS. Atuando sob este princípio, os residentes, quando finalizassem sua atuação na RMISPS, deixariam os profissionais, estudantes e usuários dos serviços mobilizados, pois os sujeitos passam, mas se as práticas forem sensibilizadas, terão melhores chances de transformar a realidade onde estão inseridos.

Como no depoimento abaixo, a integração entre serviços de saúde com a gestão e instituições de ensino possibilitam a transformação da prática dos serviços de saúde:

É um trabalho articulado com os sistemas de saúde entre as várias esferas de gestão e instituições formadoras. E está procurando transformar na prática. (E7)

Diante da complexidade e dinamicidade das instituições de saúde, as quais estão inseridas em um contexto que implica mudanças cada vez mais constantes, os profissionais precisam ter um espaço para refletir sobre suas ações. ${ }^{20} \mathrm{~A}$ residência multiprofissional proporciona aos profissionais este espaço para o pensar e fazer no trabalho, assim se concebe um ser que constrói e destrói guiado por valores políticos, culturais e éticos. ${ }^{21}$

Da mesma forma, o Projeto Político Pedagógico da RMISPS salienta que o residente necessita internalizar uma atitude crítico reflexiva, que se traduza em comprometimento com as metodologias que propiciam este tipo de formação, e que viabilizem uma maior resolutividade das ações de saúde em todos os níveis de complexidade. Tudo isso, para futuramente dispersar estas atitudes como profissional da saúde inserido nos serviços de atenção à saúde. Nesta perspectiva, seriam disparadores da EPS e desencadeadores de "um intenso movimento de forças criativas, mobilizando energias e propostas inovadoras". 22:64

A Educação Permanente em Saúde, em sua abordagem conceitual, pontua que a partir da reflexão das práticas problematizadas nos serviços, estas devem ser transformadas a fim de corresponder às necessidades dos usuários, do serviço, da gestão e do ensino. ${ }^{23}$ Sendo assim, é necessário reconhecer os facilitadores e os dificultadores da disseminação de EPS nos espaços de formação e trabalho, para a criação de novos 


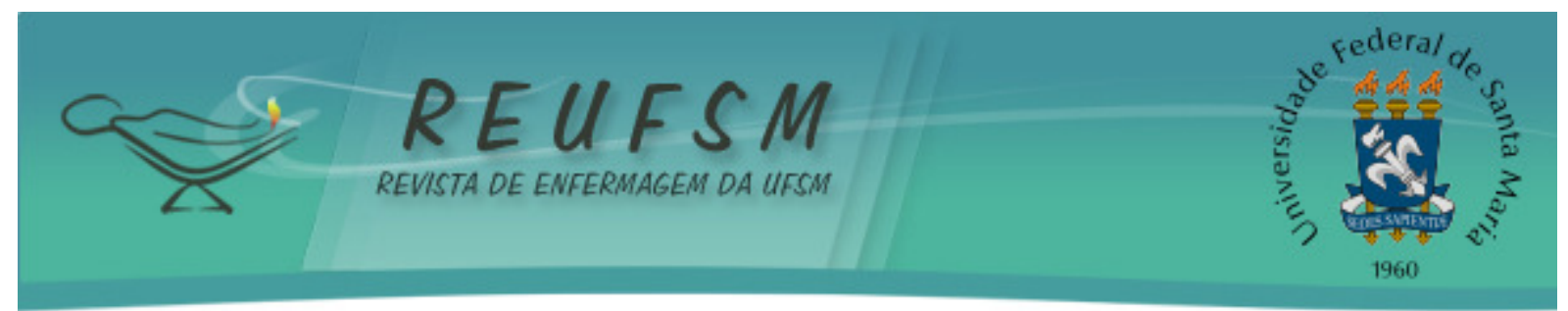

métodos, visto que a EPS já criou um caminho a ser traçado nos serviços de saúde, e que possui incentivadores para continuar o processo. ${ }^{24}$

Nesta linha de pensamento, a Educação Permanente em Saúde insere-se como alternativa de transformação do trabalho na área da saúde, aderindo a novas atividades como a atuação crítica, reflexiva, compromissada e tecnicamente eficiente. ${ }^{25}$

\section{CONSIDERAÇÕES FINAIS}

Os depoimentos dos profissionais da RMISPS mostram pontos chaves que balizam a PNEPS como: reflexão de práticas reais, transformação dos serviços em saúde baseados na necessidade da população, multidisciplinaridade, enfatizando como eixo da EPS a articulação das esferas de atenção e gestão e a integração de teoria com a prática. Esta percepção torna possível observar a RMS, como um espaço que possibilita uma formação que aproxima o profissional de saúde da realidade social e da sua atuação no SUS.

É importante salientar que espaços, como seminários de núcleo e campo, foram importantes estratégias para a disseminação da educação permanente e considerados fundamentais para a discussão das práticas vivenciadas na realidade dos serviços de saúde. Também se destaca que os profissionais da RMS salientam a integração teoria e prática como desencadeadora da EPS, a qual impulsiona a mudança da lógica da formação fragmentada ainda presente nas instituições formadoras, com intuito de promover uma rede de saberes entre os vários campos de conhecimento e suprimir a dicotomia entre teoria e prática.

No que se refere à percepção da EPS no cotidiano de atuação dos profissionais entrevistados, destacou-se que esta vai além de uma perspectiva pontual, sendo desencadeada por espaços nos quais atores dialogam acerca da educação permanente a fim de que esta possa contribuir para o desenvolvimento de competências para atuação no SUS. Ainda, espera-se que esta atuação promova nos residentes a sensibilização à atitudes críticas reflexivas e à atuação como articuladores participativos na identificação de situações compreendidas como nós críticos, assim como na criação de alternativas estratégicas inovadoras na atenção e gestão indispensáveis para as mudanças que visam a consolidação do SUS.

Por fim, essa investigação ajudou a ampliar o diálogo em torno da problemática da EPS, contextualizando-a no espaço da RMISPS em busca das lacunas que ainda inviabilizam sua real disseminação e consolidação como política. Entre estas lacunas, pode-se pontuar que a EPS abarca alguns dos mesmos obstáculos que o SUS enfrenta para sua consolidação, principalmente no que se refere à perpetuação das práticas contra-hegemônicas, ainda presentes na formação dos profissionais de saúde.

Torna-se relevante ressaltar que esse estudo, por se tratar de um Estudo de Caso, está limitado por um espaço delimitado, por um tempo e por um contexto específico. Logo, o aprofundamento da pesquisa refere-se às características delimitadas a RMISPS em que a pesquisa foi realizada, sendo apresentadas em contexto real e em profundidade. Assim, considerando-se as particularidades aqui enunciadas, sugerem-se novas investigações sobre a temática abordada a fim de que revele outros aspectos não identificados.

\section{REFERÊNCIAS}

1. Ministério da Saúde (BR). Secretaria de Gestão do Trabalho e da Educação na Saúde. Departamento de Gestão da Educação em Saúde. A educação permanente entra na roda: polos de educação permanente em saúde: conceitos e caminhos a percorrer. Brasília (DF): Ministério da Saúde; 2004. 


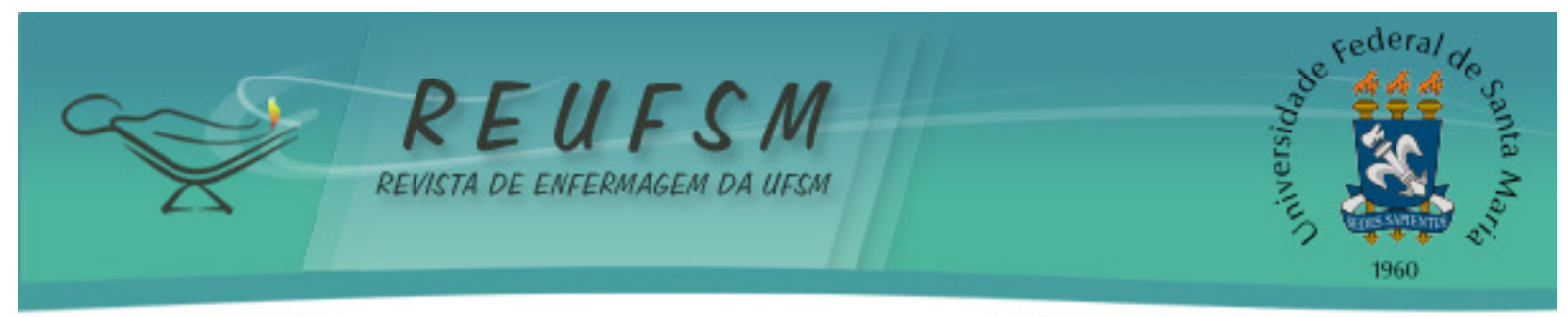

2. Ministério da Saúde (BR). Secretaria de Gestão do Trabalho e da Educação na Saúde. Departamento de Gestão da Educação na Saúde. A educação permanente entra na roda: pólos de educação permanente em saúde: conceitos e caminhos a percorrer. 2a ed. Brasília (DF): Ministério da Saúde; 2005. (Série C. Projetos, Programas e Relatórios) (Educação na Saúde).

3. Lino MM, Backes VMS, Ferraz F, Prado ML, Fernandes GFM, Silva LAA, et al. Educação permanente dos serviços públicos de saúde de Florianópolis, Santa Catarina.Trab Educ Saúde [Internet]. $2009 \mathrm{mar} /$ jun [acesso em 2012 nov 23];7(1):115-36. Disponível em: http://www.scielo.br/pdf/tes/v7n1/06.pdf.

4. Feuerwerker LCM. Mudanças na educação médica e residência médica no Brasil. São Paulo: Hucitec; 1998. 190 p.

5. Feuerwerker LM, Ceccim RB. O quadrilátero da formação para a área da saúde: ensino, gestão, atenção e controle social. Physis [Internet]. 2004 [acesso em 2012 dez 5];14(1):4165. Disponível em: http://www.scielo.br/pdf/physis/v14n1/v14n1a04.pdf.

6. Lobato CP. Formação dos trabalhadores de saúde na residência multiprofissional em saúde da família: uma cartografia da dimensão política [tese]. Londrina (PR): Universidade Estadual de Londrina; 2010.

7. Martins GA. Estudo de caso: uma estratégia de pesquisa. São Paulo: Atlas; 2006. 101 p.

8. Minayo MCS. O desafio do conhecimento: pesquisa qualitativa em saúde. $8^{\mathrm{a}}$ ed. São Paulo: Hucitec; 2010.

9. Conselho Nacional de Saúde (BR). Resolução n. 196/96: dispõe sobre pesquisa envolvendo seres humanos. Brasília (DF) [acesso em 2012 dez 7]. Disponível em: http://www.ufrgs.br/bioetica/res19696.htm.

10. Merhy EE. O SUS e um dos seus dilemas: mudar a gestão e a lógica do processo de trabalho em saúde (um ensaio sobre a micropolítica do trabalho vivo). In: Fleury $\mathrm{S}$, organizadora. Saúde e democracia: a luta do CEBES. São Paulo: Lemos Editorial; 1997. p 125-42.

11. Franco TB, Chagas RC, Franco, CM. Educação permanente como prática. In: Pinto S, Franco TB, Magalhães MG, organizadores. Tecendo redes: os planos da educação, cuidado e gestão na construção do SUS; a experiência de Volta Redonda-RJ. São Paulo: Hucitec; 2012.

12. Silva LAA, Bonacina DM, Andrade A, Oliveira TC. Desafios na construção de um projeto de educação permanente em saúde. Rev Enferm UFSM [Internet]. $2012 \mathrm{set} / \mathrm{dez}$ [acesso em 2013 ago 24];2(3):496-506. Disponível em: http://cascavel.ufsm.br/revistas/ojs2.2.2/index.php/reufsm/article/view/5364.

13. Ceccim RB, Armani TB, Oliveira DLLC, Bilibio LF, Moraes M, Santos ND. Imaginários da formação em saúde no Brasil e os horizontes da regulação em saúde suplementar. Ciênc Saúde Colet [Internet]. 2008 [acesso em 2012 nov 13];13(5):1567-78. Disponível em: http: / / www.scielo.br/scielo.php?pid=S1413-

$81232008000500021 \&$ script=sci_abstract\&tlng=pt.

14. Ministério de Educação (BR) Câmara de Educação Superior. Diretrizes Curriculares Nacionais de Graduação em Enfermagem, Medicina e Nutrição. Brasília (DF): Ministério da Saúde; 2001.

15. Merhy EE. Saúde: a cartografia do trabalho vivo. São Paulo: Hucitec; 2002. 


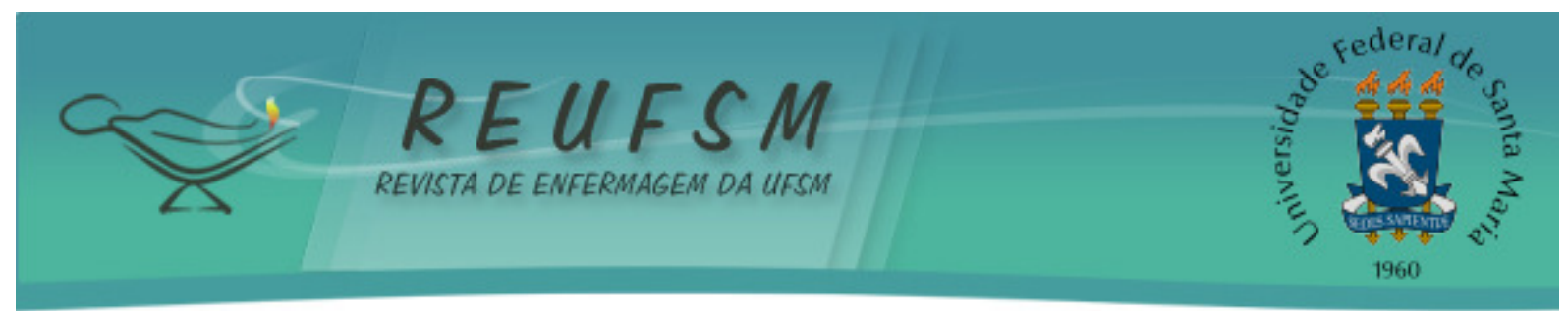

16. Franco TB. Healthcare production and pedagogical output: integration of healthcare system settings. Interface Comun Saúde Educ [Internet]. 2007 [acesso em 2012 dez 12];(11)23:427-38. Disponível em: http://www.scielo.br/scielo.php?pid=\$1414$2832007000300003 \&$ script=sci_arttext.

17. Merhy EE. Em busca do tempo perdido: a micropolítica do trabalho vivo em saúde. In: Merhy EE, Onocko R, organizadores. Agir em saúde: um desafio para o público. 2a ed. São Paulo: Hucitec; 2002. p. 71-112.

18. Ceccim RB. A educação permanente em saúde e as questões permanentes à formação em saúde mental. In: Caderno Saúde Mental: os desafios da formação, Belo Horizonte (MG): ESP-MG; 2010. v. 3.

19. Silva LAA, Leite MT, Hildebrandt LM, Pinno C. Educação Permanente em Saúde na ótica de membros das comissões de integração ensino-serviço. Rev Enferm UFSM [Internet]. 2013 mai/ago [acesso em 2013 set 22];3(2):296-306. Disponível em:http://cascavel.ufsm.br/revistas/ojs-2.2.2/index.php/reufsm/article/view/8476.

20. Merhy EE, Feuerweker LCM, Ceccim RB. Educación permanente em salud uma estrategia para intervenir em la micropolítica del trabajo em salud. Salud Colect [Internet]. 2009 mai/ago [acesso em 2012 out 20];2(2):147-60. Disponível em: http://www.scielo.org.ar/scielo.php?pid=S185182652006000200004\&script=sci_arttext.

21. Silva CT, Terra MG, Padoin SMM, Ceolin S, Lacchini AJB, Lavich CRP. Percepções de enfermeiros sobre educação permanente em saúde em um hospital de ensino. Rev Pesqui Cuid Fundam (Online) [Internet]. 2011 jul/set [acesso em 2013 jun 10];3(3):2286-96. Disponível http://www.seer.unirio.br/index.php/cuidadofundamental/article/.../1397.

em:

22. Ricaldoni CAC, Sena RR. Educação permanente: uma ferramenta para pensar e agir no trabalho de enfermagem. Rev Latinoam Enferm [Internet]. 2006 [acesso em 2012 nov 14];14(6):837-4. Disponível em: http://www.scielo.br/pdf/rlae/v14n6/pt_v14n6a02.pdf.

23. Malta DC, Merhy EE. A micropolítica do processo de trabalho em saúde: revendo alguns conceitos. REME Rev Min Enferm [Internet]. 2003 [acesso em 2012 set 25];7(1):61-6. Disponível em: http://www.enf.ufmg.br/site_novo/modules/mastop_publish/?tac=Vol._7_n\%BA_1_jan_.\% 2Fjun._2003.

24. Ceccim RB. Educação permanente em saúde: desafio ambicioso e necessário. Interface Comun Saúde Educ [Internet]. 2005 [acesso em 2013 jun 10];16(9):161-77.Disponível em: http://www.scielo.br/pdf/icse/v9n16/v9n16a13.pdf.

25. Amestoy SC, Schveitzer MC, Meirelles BHS, Backes VMS, Erdmann AL. Paralelo entre educação permanente em saúde e administração complexa. Rev Gaúch Enferm [Internet]. 2010 jun [acesso em 2013 jun 12];31(2):383-7. Disponível em: http: //www.scielo.br/pdf/rgenf/v31n2/25.pdf.

Data de recebimento: $20 / 10 / 2013$

Data de aceite: 09/01/2014

Contato com autor responsável: Cristiane Trivisiol da Silva

Endereço postal: Rua Appel, N44, apt: 205, Residencial Araucárias, Porto Alegre, RS, Brasil.

E-mail: cris.trivisiol@gmail.com 